\title{
First record of Nubensia nubens (Edwards 1929) (Diptera: Chironomidae) for Bulgaria
}

\author{
Dimitriy Dashinov ${ }^{1 *}$ and Ladislav Hamerlik ${ }^{2}$ \\ ${ }^{1}$ Department of General and Applied Hydrobiology, Biological faculty, Sofia University "St. Kliment \\ Ohridski”, Bulgaria \\ ${ }^{2}$ Faculty of Natural Sciences, Matej Bel University, Tajovského 40, SK-974 01 Banská Bystrica, Slovakia \\ E-mail: ddashinov@abv.bg
}

\begin{abstract}
Nubensia nubens (Edwards 1929) is reported for the first time in Bulgaria from two lowland rivers, tributaries of the Danube (eastern Europe). Larvae of the species were found incidentally in samples collected for an ichthyological study, in the gut contents of Neogobius melanostomus (Pallas 1814) (Actinopterygii: Gobiidae), and in a benthic sample. The habitat conditions at the corresponding sites differed from those of previous records. Our finding underlines the potential of non-standard supporting methods, such as analyzing fish gut contents for discovering rare species that are hard to record by standard hydrobiological methods.
\end{abstract}

\section{Introduction}

Recently the larvae and adult female of Nubensia nubens (Edwards 1929) were described and placement of the species in a separate genus was suggested (Spies and Dettinger-Klemm 2015). Older records referred to the species under different names, for example, "Polypedilum (Pentapedilum) nubens Edwards, 1929" (e.g. Sæther and Spies 2013), "Polypedilum sp. A" for subfossil larvae (Brooks et al. 2007: 102); for a complete list of synonyms, see Spies and Dettinger-Klemm (2015: 110). The species has been reported from many countries in Europe (Czech Republic, France (including Corsica), Great Britain (including Northern Ireland), Ireland, Italy, North Macedonia, Norway, Portugal, Spain, Switzerland; see Sæther and Spies 2013) and from more eastern parts of the Palaearctic region (Armenia, Azerbaijan, Georgia, Iran, Iraq, Israel, Jordan, Lebanon, Russia, Syria, Turkey; see Oyewo and Sæther 2008). In addition, Bitušík and Trnková (2019) gave a new record from Albania, based on a single pupal exuviae. Moreover, N. nubens has been recorded very recently in Croatia (from Vrana Lake; Dorić et al., unpublished) and in Malta (A. Móra, pers. comm.).

The present study focuses on two Bulgarian tributaries flowing into the Bulgarian-Romanian sector of the Danube River (Eastern Europe). A detailed list of Chironomidae (231 taxa in total) from this region was compiled about 25 years ago (Russev et al. 1994) with no subsequent major contributions or revisions. In it, there are no records of the older synonyms of $N$. nubens. More recently, hydrobiological studies have produced taxonomic lists of the Chironomidae from standing water bodies in the same region (Trichkova et al. 2013); however, no synonyms of $N$. nubens are mentioned. Thus, this paper gives the first record of Nubensia nubens (Edwards 1929) for the Bulgarian fauna.

\section{Material and methods}

The study area includes the Iskar and Vit rivers, which flow in northern Bulgaria (Table 1). Both rivers are lowland tributaries of the Danube (R7 river type according to the Water Framework Directive (WFD) river typology (Directive 60/2000/EC; Cheshmedjiev et al. 2010)). The Iskar River is the longest inland river in Bulgaria with a length of $368 \mathrm{~km}$ and a discharge of $54.5 \mathrm{~m}^{3} \mathrm{~s}^{-1}$ (Hristova 2012). At the sampling point bottom sediments included mainly gravel and pebbles with silt and sand accumulated near the riverbank. The Vit River is $188 \mathrm{~km}$ long with a discharge of $14.3 \mathrm{~m}^{3} \mathrm{~s}^{-1}$ (Hristova 2012). The bottom substrate is composed mostly of shale bedrock, with zones of gravel and pebbles. Submerged vegetation was present in both rivers, mostly Myriophyllum spp., Najas minor All. and Stuckenia pectinata (L.) Börmer.

Sampling on the Vit and Iskar rivers was conducted on $1^{\text {st }}$ and $5^{\text {th }}$ October 2017, respectively. At each sampling site, physical and chemical parameters, such as water temperature, $\mathrm{pH}$, oxygen concentration and conductivity, were measured using portable devices (Hanna Inc.). Water velocity was measured with a portable water flow probe (model FP101, Global Water Instrumentation, Inc., USA). Fish and macroinvertebrate samples were collected for an ichthyological study using electrofishing (SAMUS, 200/350 V, 3/12 A, 45-50 $\mathrm{Hz}$ ) and a Hess sampler (ISO 8265:1988; frame size 0.3 by $0.3 \mathrm{~m}$; mesh size $0.5 \mathrm{~mm}$ ). 
Table 1. Basic characteristics of sampling sites where $N$. nubens was recorded.

\begin{tabular}{|c|c|c|c|}
\hline & Unit & Vit River & Iskar River \\
\hline \multirow{2}{*}{ Coordinates } & & $\mathrm{N} 43.4078694^{\circ}$ & $\mathrm{N} 43.5186500^{\circ}$ \\
\hline & & E $24.5217917^{\circ}$ & E $24.2250194^{\circ}$ \\
\hline Altitude & m a.s.l. & 63 & 51 \\
\hline Distance form Danube & $\mathrm{km}$ & 53 & 41 \\
\hline Temperature & ${ }^{\circ} \mathrm{C}$ & 15.9 & 14.0 \\
\hline Oxygen concentration & $\mathrm{mg} \mathrm{L}^{-1}$ & 13.4 & 9.0 \\
\hline Oxygen saturation & $\%$ & 133 & 100 \\
\hline $\mathrm{pH}$ & & 9.9 & 9.3 \\
\hline Conductivity & $\mu \mathrm{S} \mathrm{cm}-1$ & 483 & 446 \\
\hline Flow velocity & $\mathrm{m} \mathrm{s}^{-1}$ & 0.4 & 0.3 \\
\hline
\end{tabular}

From the obtained benthic samples and fish gut contents, Chironomidae larvae and pupae were sorted and identified. Head capsules of the larvae were mounted on permanent slides with Swann's solution. Individuals of Nubensia nubens were identified using the larva description by Spies and Dettinger-Klemm (2015). The morphology of our larvae agrees in all described details. The identified material was deposited in the Dipterological collection of the Department of General and Applied Hydrobiology, Sofia University, Bulgaria.

\section{Results and discussion}

Larvae of Nubensia nubens were observed both in fish gut contents and macrozoobenthic samples. A single individual was found intact in the gut of a Neogobius melanostomus from the Iskar River (Fig. 1), where other invertebrates (mostly Chironomidae) contributed to the overall gut content. Most Chironomidae larvae and pupae in the analysed guts were only slightly damaged due to digestion and taxonomically distinguishable (a total of 26 genera were observed in 350 fish: unpublished data). A single larva of $N$. nubens was found in a benthic sample from the Vit River taken from gravel and cobble substrate and submerged vegetation.

Most of the previous records of $N$. nubens are from standing water bodies and fine substrates (Moller Pillot 2013; Murray et al. 2015; Spies \& Dettinger-Klemm 2015) with only few records from fast flowing rivers (Michiels 2004 cited in Moller Pillot 2013). The present report is from a lowland river with coarse bottom substrate. Several small lakes and ponds are situated across the Vit River's left bank, near the sampling point: it cannot be excluded that the observed individual originated from these standing water bodies. This could explain the low abundance of N. nubens in the sample, while Spies and Dettinger-Klemm (2015) reported $>1000$ individuals $/ \mathrm{m}^{2}$ in summer, however this might be also due to the season of sampling and/ or differences in habitat type. There are no such standing water bodies near the sampling site of the Iskar River. Here the examined material was part of fish gut contents so it might have originated from a variety of sections in the river - pools or slow flowing bankside mesohabitat. Nubensia nubens is thought to live mainly in waters with low conductivity $\left(<200 \mu \mathrm{S} \mathrm{cm}^{-1}\right)$ (Ruse 2002 cited in Moller Pillot 2013), while in the present study the species was recorded from water with higher conductivity ( $>400 \mu \mathrm{S} \mathrm{cm}^{-1}$, Table 1).

The material sampled by Spies and Dettinger-Klemm (2015) is from eutrophic waters. In contrast, the rivers studied by us are water bodies with "good" ecological status (Dashinov personal observations following Directive 60/2000/EC). The records of $N$. nubens from Albania are also from oligotrophic waters (Schneider et al. 2014; Bitušík and Trnková 2019). In these cases, however, the species was observed in very low abundances. Thus, larvae of $N$. nubens appear to be thriving more in eutrophic waters, as Spies and Dettinger-Klemm (2015) observed. While the present record of Nubensia nubens is the first one for Bulgaria, there are probably more suitable habitats in the Bulgarian Danube basin that the species might occupy, but this needs to be evaluated by further studies. 

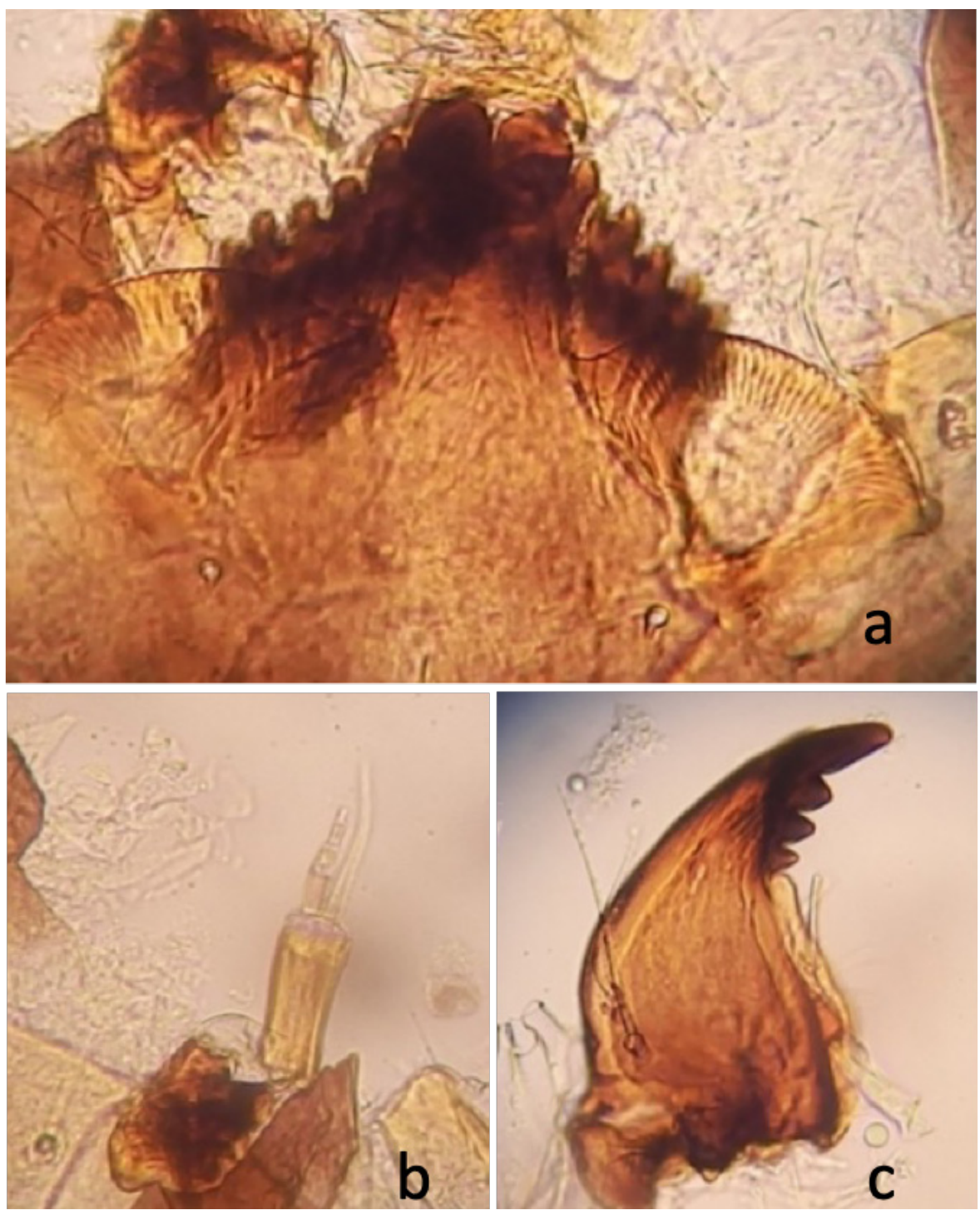

Figure 1. Photos of Nubensia nubens from the gut of Neogobius melanostomus a. mentum; b. antenna; c. mandible. Photo D. Dashinov

\section{Acknowledgments}

We would like to thank PhD-student Emil Kanev for his help in sample collection. We thank the anonymous reviewer for his thoughtful edits of the manuscript.

\section{References}

Bitušík, P. and Trnková, K. 2019. A preliminary checklist of Chironomidae (Diptera) from Albania with first records for the Balkan Peninsula. - Zootaxa 4563(2): 361-371. http://dx.doi.org/10.11646/zoo$\underline{\text { taxa.4563.2.9 }}$

Brooks, S.J., Langdon, P.G. and Heiri, O. 2007. The identification and use of Palaearctic Chironomidae larvae in palaeoecology. Technical Guide 10. Quaternary Research Association, vi $+276 \mathrm{p}$.

Directive 2000/60/EC of the European Parliament and of the Council of 23 October 2000 establishing a framework for Community action in the field of water policy. Official Journal of the European Communities 22.12.2000.

Dorić, V., Koh, M. and Mihaljević, Z. (submitted) First record of species Nubensia nubens (Edwards, 1929) (Diptera: Chironomidae) from Croatia. - Natura Croatica.

Hristova, H. 2012. River waters of Bulgaria. Tip-top press, Sofia, Bulgaria 830 p. (In Bulgarian) 
Moller Pillot H. 2013. Chironomidae Larvae of the Netherlands and Adjacent Lowlands. Biology and Ecology of Chironomini. KNNV Publishing, 272 p.

Murray, D. A., Langton, P. H., O'Connor J. P. and Ashe, P. J. 2015. Distribution records of Irish Chironomidae (Diptera): part 3 - Chironominae. Bulletin of the Irish Biogeographical Society 39: 7-192.

Oyewo, E. A., and Saether, O. A. (2008). Revision of Polypedilum (Pentapedilum) Kieffer and Ainuyusurika Sasa et Shirasaki (Diptera: Chironomidae). Zootaxa 1953: 1-145.

Russev B, Yaneva I, and Karapetkova M. (1994). Hydrobiology In Russev, B. (Ed.) Limnology of the Bulgarian Danube tributaries, Book Tiger publishing, 130-234. (In Bulgarian)

Sæther, O.A. and Spies, M. 2013. Fauna Europaea: Chironomidae. In Beuk, P. and Pape, T. (Eds.) Fauna Europaea: Diptera Nematocera. Fauna Europaea version 2.6. https://fauna-eu.org/.

Schneider, S. C., Cara, M., Eriksen, T. E., Goreska, B. B., Imeri, A., Kupe, L., Lokoska, T., Patceva, S., Trajanovska, S., Trajanovski, S., Talevska, M. and Sarafiloska, E. V. 2014. Eutrophication impacts littoral biota in Lake Ohrid while water phosphorus concentrations are low. Limnologica 44: 90-97. https://doi. org/10.1016/j.limno. 2013.09.002

Spies, M., and Dettinger-Klemm, A. 2015. Diagnoses for Nubensia, n. gen. (Diptera, Chironomidae, Chironomini), with the first full descriptions of the adult female and larva of $N$. nubens (Edwards, 1929). Zootaxa 3994(1): 109-121. https://doi.org/ 10.11646/zootaxa.3994.1.5

Trichkova, T., Tyufekchieva, V., Kenderov, L., Vidinova, Y., Botev, I., Kozuharov, D., Hubenov,Y., Uzunov, S., Stoichev, S. and Cheshmedjiev, S. (2013). Benthic macroinvertebrate diversity in relation to environmental parameters, and ecological potential of reservoirs, Danube River Basin, North-West Bulgaria. Acta zoologica bulgarica 65(3): 337-348.

Article submitted 18. February 2020, accepted by Peter H. Langton 6. May 2020, published 19. May 2020. 